\title{
On the Role of Retaliation in Trade Agreements*†
}

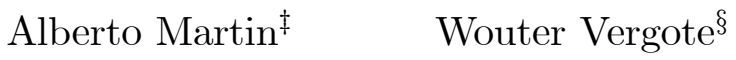

This version: April 2008

(First Version: June 2005)

\begin{abstract}
This paper analyzes the role of retaliation in trade agreements. It shows that, in the presence of private information, retaliation can always be used to increase the welfare derived from such agreements by the participating governments. In particular, it is shown that retaliation is a necessary feature of any efficient equilibrium.

We argue that retaliation would not be necessary if governments could resort to international transfers or export subsidies to compensate for terms-of-trade externalities. Within the current world trading system, though, in which transfers are seldom observed whereas export subsidies are prohibited, the use of the remaining trade instruments in a retaliatory fashion might be optimal. The model is used to interpret the retaliatory use of antidumping observed in the last decades, and the proliferation of these measures relative to other trade remedies.
\end{abstract}

Keywords: Tariffs, Retaliation, Asymmetric Information, WTO, Antidumping Duties

JEL Classification: C72,D82,F13.

\footnotetext{
${ }^{*}$ We are deeply indebted to Kyle Bagwell for constant encouragement. We are particularly grateful to Chad Bown, Ronald Findlay, Robert Staiger, Hylke Vandenbussche, and two anonymous referees for comments and suggestions. The paper has also benefited from discussions with Atila Abdulkadiroglu, Filippo Taddei, Guido Sandleris and seminar participants at Columbia University, CREI, ETSG Athens, University of Maastricht, HEC Montréal, UQAM, ITAM, University of Louvain, University of Namur and Bowdoin College. Martin gratefully acknowledges financial support from the Spanish Ministry of Education and Science (grant SEJ2005-01126 and Juan de la Cierva Program), from the Generalitat de Catalunya (DURSI, grant SGR2005 0049) and from CREA-Barcelona Economics. Vergote gratefully acknowlegdes support from the Belgian Federal Government (contract IAP P6/09).

†An earlier version of this paper was circulated as "Antidumping: Welfare Enhancing Retaliation?".

${ }^{\ddagger}$ CREI and Universitat Pompeu Fabra, CEPR.

${ }^{\S}$ Corresponding Author. CEREC, Facultés universitaires Saint-Louis and CORE, Université Catholique de Louvain. 38, Boulevard du Jardin Botanique, 1000 Brussels, Belgium. Phone: +32 2 7879317, fax +32 22117997 , e-mail:vergote@fusl.ac.be
} 


\section{Introduction}

In 1999, the Unites States imposed punitive tariffs on nine types of European goods. These tariffs, part of what became known as the "banana war", had the objective of retaliating against Europe's restrictions on the import of bananas. In 2002, another trade war loomed on the horizon when the United States introduced temporary tariffs on imported steel. Amidst wide media coverage, the European Union announced that it would impose retaliatory tariffs. This threat of retaliation eventually led the United States to back down and withdraw the tariffs before schedule. These recent episodes are only two of many to highlight the increasing importance of actual and threatened retaliation in trade relationships. Despite its importance, though, retaliation is not yet fully understood from a conceptual viewpoint. Does it imply a breakdown in cooperation among countries? Is it best interpreted as a crucial part of cooperation? If so, what is it that retaliation does for cooperation?

The goal of this paper is to analyze the role of retaliation in trade agreements. Its main result consists in showing that in the presence of private information, and provided that they are sufficiently patient, governments can always use retaliation to increase joint welfare in a trade relationship. Moreover, it is shown that governments who are arbitrarily patient must necessarily resort to retaliation if they are to maximize their joint welfare.

We study a two good, two country model of trade in which countries interact repeatedly. It is assumed that the preferences of governments are subject to random shocks that affect their relative valuation of the import competing sector. In our setup, governments would benefit from having the flexibility to raise their import tariffs when their valuation of the import competing sector is high, and to decrease them otherwise. It is assumed, however, that governments cannot observe the preferences of their trading partner. This feature gives rise to a problem of incentive compatibility: since governments always have an incentive to set relatively high tariffs in order to affect the terms of trade in their favor, they have a tendency to overstate their preference for protection at any point in time. To prevent them from doing so, there must be some cost associated to the use of high tariffs.

This paper analyzes different ways in which such a cost can be imposed, and concludes that when governments only have access to import tariffs - some retaliation is always desirable. We first consider a basic scenario in which governments can resort to direct transfers or to export subsidies. In both of these cases, governments can be encouraged to tell the truth without sacrificing joint welfare. When transfers are available, governments can be simply forced to pay their trading partners for the terms-of-trade effects of their chosen tariff levels. In the presence of subsidies, the 
terms-of-trade effects of the tariffs chosen by the importing country can be neutralized by letting the exporting country adjust its export subsidies. However, since compensating transfers are not observed in the world and the use of export subsidies is restricted under GATT/WTO, we then shift our attention to the more realistic environment in which none of these policy instruments are available.

In such a scenario, the only trade policy instruments that governments control at any point in time are import tariffs. Thus, if governments are to be truthful about their preference for protection, higher tariffs from any one of them must be associated to a cost in the form of higher tariffs from their trading partner. These higher tariffs from their trading partner, in turn, can take place either contemporaneously or be delayed into the future. We refer to the former situation as one of reciprocity. The latter possibility, in turn, is referred to as retaliation.

Our main results are that: (i) if governments are sufficiently patient, any equilibrium that is based on reciprocity can be outperformed by an alternative equilibrium that introduces some degree of retaliation, and; (ii) if governments are arbitrarily patient, retaliation is a necessary feature of any equilibrium that maximizes joint welfare.

The intuition for the first result is as follows: as was said earlier, governments in our model find it optimal to allow import tariffs to vary with their desired levels of protection. In an equilibrium based on reciprocity, though, incentive compatibility stems from the fact that each country's tariffs are directly related to the contemporaneous tariffs of its trading partner. Hence, tariffs are never set at their optimal levels, since in each period they are jointly used to accommodate governments' shifting preferences for protection and to provide incentives for truthtelling. One could imagine an alternative equilibrium in which governments sometimes set tariffs at their optimal levels and sometimes punish one another by setting tariffs at relatively high levels. When setting tariffs optimally, governments are provided with incentives to be truthful by letting higher tariffs be associated with an increased probability of punishment in the future. The payoff of governments in such an equilibrium, which is a linear combination of the optimal payoffs and the expected payoffs from the punishment phases, is shown to be higher than the payoffs attainable under reciprocity provided that governments are sufficiently patient.

Our second result, that the maximization of joint welfare requires retaliation on the equilibrium path, is an application of the theoretical findings of Fudenberg et al. (1994). They established the conditions under which efficient cooperation is possible in a class of repeated games with private information. In our model, efficient cooperation requires truthtelling, which in turn can only arise if high tariffs today lead to lower payoffs tomorrow. Truthtelling, however, is by itself not enough. It is also necessary that truthtelling is induced without sacrificing future welfare. This can only 
be achieved by aligning incentives through the redistribution of future welfare among governments, while preserving the level of joint welfare intact. But this means that whenever a government's expected welfare from cooperation decreases, that of the other government must increase: in a world in which the only policy tool available to governments is the use of import tariffs, this implies that there must be retaliation in equilibrium.

Having derived these theoretical results, we then draw on their insights to provide an explanation for the use of different trade remedies and exceptions permitted by the GATT/WTO. Our main results imply that, in a world of restricted trade instruments, governments can gain from using the remaining ones in a flexible way. This flexibility, though, must be subject to some type of control. Within the context of the WTO, there are two main channels to control potential deviations, namely: a) to retaliate directly through the application of AD or safeguards, or; b) to challenge them in the context of the Dispute Settlement Understanding (DSU). ${ }^{1}$ We first focus on the use of trade remedies, and note that there is a striking difference between the use of $\mathrm{AD}$ and the use of safeguards. The use of $\mathrm{AD}$ measures has increased significantly over the last two decades, and so has the number of countries using them. Safeguards, on the other hand, have remained relatively unused. Why are countries resorting to AD? An increasing body of empirical evidence suggests that $\mathrm{AD}$ measures are not being used to counter the existence of dumping, but rather in a strategic or retaliatory fashion. ${ }^{2}$ We argue that this is consistent with our results, since - like tariffs in our model - AD measures can be used somewhat arbitrarily and they can be targeted to specific trading partners. Safeguards, on the other hand, are harder to impose and they must adhere to the principle of non-discrimination. On a different note, governments could also use the DSU to challenge trade measures. But why would they use a costly and uncertain system to do so, if they can retaliate directly? Indeed, existing evidence indicates that few remedies are challenged within the context of the DSU. Moreover, governments are less likely to pursue cases in the DSU on behalf of industries that can retaliate directly through a reciprocal AD measure of its own. As Bown (2005) states, this is "consistent with the theory that WTO complainants may be avoiding WTO litigation in favor of pursuing reciprocal antidumping and hence vigilante justice".

To summarize, AD has been used increasingly in the last few decades, and much of this use has been related to strategic or retaliatory motives. This has led many to argue in favor of eliminating this policy tool altogether. ${ }^{3}$ Our model suggests a different view by which, as countries join the

\footnotetext{
${ }^{1}$ Bown $(2002,2005)$ provides evidence on the use of safeguards and of the DSU.

${ }^{2}$ See Prusa and Skeath (2002, 2004), Blonigen and Bown (2003), Finger (1993) and Feinberg and Reynolds (2006) for evidence regarding the impact of retaliation, and of the threat of retaliation, on the use of AD measures. This evidence is discussed in Section 6.

${ }^{3}$ Klitgaard and Schiele (1998), for example, criticize both the theory behind AD regulations and the way in which they are applied. Regarding the former, they consider the concept of dumping itself to be seriously flawed from
} 
WTO system and in doing so lose some of their policy instruments, the retaliatory use of the remaining ones might be an optimal way for governments to accommodate shocks. Our underlying argument is thus conceptually very simple: once governments are refrained from freely using all their instruments, it might well be that a retaliatory use of the remaining ones enhances the value of cooperation. Note how this notion is reminiscent of Tinbergen's (1967) work regarding the relationship between the number of available policy instruments and the number of policy targets. In designing rules for international cooperation, it must be considered that the elimination of some instruments which are normally available to governments might trigger the use of the remaining ones in new and unforeseen ways. In our particular setup, this is exactly the case of retaliation, which may increase the value of trade agreements when the use of other instruments is restricted but the objectives to be attained remain unchanged.

Our model displays interesting characteristics at different levels. In the first place, it analyzes retaliation within the context of strategic interaction between governments. This framework has been increasingly useful in understanding the role of the world trade system and its particular regulations, and our analysis of retaliation is compatible with existing research in this direction. Second, the introduction of private information is relatively unexplored within the aforementioned framework. Private information brings two important features to the model.

The first is realism, since it seems natural to assume that governments have some degree of private information when interacting with one another. The introduction of private information allows us to treat a fundamental tension between collectively wanting to share information in order to cooperate, and facing a desire to lie about their information in their own favor.

The second is the ability of private information to naturally generate retaliation in equilibrium. In the absence of private information, of course, asymmetric punishment schemes can be useful in supporting cooperation. In these cases, though, punishments merely prevent agents from deviating and are therefore never observed in equilibrium. ${ }^{4}$ Alternatively, retaliatory equilibria are possible in settings without private information (e.g. tit for tat), but they are necessarily inefficient in these cases. In contrast, in a setting of private information, some degree of retaliation is necessary in order to enhance cooperation.

Within the trade literature, our paper is related to the work of Bagwell and Staiger (2005), Feenstra and Lewis (1991), Hungerford (1991) and Riezman (1991). Bagwell and Staiger (2005) was undertaken simultaneously with our research and deals with a repeated setting with private an economic perspective, while they also question the procedures used to review dumping allegations. In a similar spirit, Barfield (2004) argues that AD measures are "fundamentally at odds with the free trade policies that have dramatically increased global welfare over the last half century."

${ }^{4}$ In fact, in order to support pareto efficient equilibria that Pareto dominate the one-shot Nash Equilibrium, no (subgame perfect) asymmetric punishments threats are necessary as simple Nash reversion will suffice. 
information very similar to ours. The object of their paper, though, is to provide equilibrium interpretations of GATT/WTO negotiations regarding upper bounds on applied tariffs and of some features of GATT/WTO escape clauses. Although they analyze dynamic equilibria, they do not focus on the role of retaliation. Compared to their paper, we allow for more flexible dynamic tariff schemes and focus on the role of retaliation as a tool to reduce the cost of incentive compatibility. ${ }^{5}$ Feenstra and Lewis, on the other hand, deal with a static setting in which - at the moment of negotiating trade restrictions - one government has private information regarding the political pressure it faces from domestic producers. Although similar in spirit, they assume that governments behave in a cooperative manner: our setting is noncooperative and the behavior of governments is obtained as an equilibrium to a game of repeated interaction. Riezman, whose work is also very close to this paper, builds on the work of Green and Porter (1984) in order to analyze a repeated tariff game with private information. His analysis differs from ours by focusing on symmetric trade wars, in which high tariffs set by any one government today lead to lower future payoffs for all governments. By not allowing future payoffs to be distributed in an asymmetric fashion between governments, cooperation is bounded away from optimality in his setting. Finally, Hungerford analyzes a setting similar to Riezmann's while allowing for asymmetric trade wars: his emphasis, though, is not on the efficiency gains obtained through retaliation, but rather on the fact that the threat of retaliation does not suffice to attain free trade in equilibrium.

From a more general perspective, we use a mechanism design approach to repeated games with private information (Athey and Bagwell (2001), Athey et al. (2005)). This approach has been useful to study price collusion in settings of private information. Using a well designed mechanism for a repeated setting of Bertrand competition, Athey and Bagwell (2001) show that optimal collusion can be achieved. Unfortunately, their results cannot be easily generalized to other or richer settings. In this paper, we therefore develop a cooperative mechanism suitable for a repeated trade relationship with private information.

The structure of the paper is as follows: we first present the static model in Section 2 and briefly comment on its properties. Section 3 explains the basic setup and notation of the repeated model. In Section 4, equilibria of the latter are analyzed under the assumption that governments can resort to more than one instrument: in particular, we show how the model allows for efficient equilibria in the presence of transfers or export subsidies. Section 5 concentrates on the repeated model when import tariffs are the only instruments that governments can use, and it contains our

\footnotetext{
${ }^{5}$ In particular, Bagwell and Staiger (2005) find that upper bounds on tariffs might be useful for providing incentives. In our framework, governments are deterred from applying high tariffs by the threat of retaliation. In their model, though, when governments increase tariffs they diminish the gap between actual tariffs and the upper bound, thereby losing flexibility to increase them further in the future.
} 
main results regarding the welfare enhancing role of retaliation. Section 6 develops how our model and its results can be applied to the different trade remedies and exceptions permitted by the GATT/WTO. Finally, Section 7 concludes.

\section{The static model}

\subsection{Basic setup}

This section lays the foundations of the simple two country, two good model that will be used throughout the paper, which draws heavily on Bagwell and Staiger (2001). Suppose there are two countries, which we call Home $(H)$ and Foreign $(F)$, that trade two competitively-produced goods, $x$ and $y$. Each of these goods is demanded in both countries according to a symmetric demand function $D($.$) , and we assume x(y)$ to be the natural import good of Home (Foreign). Let $p_{i}^{j}$ represent the domestic price of good $i \in\{x, y\}$ in country $j \in\{H, F\}$, and let the domestic demand for good $i$ in country $j$ be represented by the linear function $D^{j}\left(p_{i}^{j}\right)=\alpha-\beta p_{i}^{j}$. As for supply functions, let them be given by $Q_{x}^{H}\left(p_{x}^{H}\right)=\gamma p_{x}^{H}$ and $Q_{y}^{H}\left(p_{y}^{H}\right)=\phi p_{y}^{H}$ in Home and by $Q_{y}^{F}\left(p_{y}^{F}\right)=\gamma p_{y}^{F}$ and $Q_{x}^{F}\left(p_{x}^{F}\right)=\phi p_{x}^{F}$ in Foreign. It is assumed that $\gamma<\phi$ in order to capture the fact that $x$ is the natural import good of Home. In the present model, countries are free to choose import tariffs and export subsidies, denoted by $\tau_{i}^{j}$ for $i \in\{x, y\}$ and $j \in\{H, F\} .{ }^{6}$

The market equilibrium of the static model is easily characterized, for given levels of import tariffs and export subsidies. Consider first the market for good $x$. For any given domestic price, Home's import function, $M_{x}^{H}$, is given by

$$
M_{x}^{H}=\alpha-(\beta+\gamma) p_{x}^{H}
$$

whereas the export function of Foreign, $E_{x}^{F}$, is given by

$$
E_{x}^{F}=(\phi+\beta) p_{x}^{F}-\alpha
$$

If we define $p_{x}^{W}$ to be the world price of good $x$, it must be the case that $p_{x}^{H}=p_{x}^{W}+\tau_{x}^{H}$, while $p_{x}^{F}=p_{x}^{W}+\tau_{x}^{F}$. Thus, replacing these expressions in (1) and (2) and solving for the value of $p_{x}^{W}$ that equals world imports and exports of good $x$, we obtain that

$$
p_{x}^{W}=\frac{2 \alpha-(\beta+\gamma) \tau_{x}^{H}-(\phi+\beta) \tau_{x}^{F}}{2 \beta+\gamma+\phi}
$$

\footnotetext{
${ }^{6}$ As a convention, we let $\tau_{i}^{j}>0$ denote a positive level of tariff (subsidy) levied on the import (export) good $i$ by country $j$.
} 
whereas domestic prices are given by

$$
\begin{aligned}
& p_{x}^{H}=\frac{2 \alpha+(\beta+\phi) \cdot\left(\tau_{x}^{H}-\tau_{x}^{F}\right)}{2 \beta+\gamma+\phi}, \\
& p_{x}^{F}=\frac{2 \alpha-(\beta+\gamma) \cdot\left(\tau_{x}^{H}-\tau_{x}^{F}\right)}{2 \beta+\gamma+\phi} .
\end{aligned}
$$

The equilibrium conditions for market $y$ are defined in an analogous manner.

\subsection{Trade policy}

As can be seen from Equations (3)-(5), trade policy affects the equilibrium prices and the volumes of trade in the markets for both goods. We now characterize governments' objectives and analyze the equilibrium trade policies in the static model under symmetric and asymmetric information.

It is assumed that the preferences of the government of country $j \in\{H, F\}$ are influenced by a political economy parameter $\zeta^{j}$, which affects its valuation of the import-competing sector. This parameter, which is drawn randomly and independently, is assumed to be uniformly distributed over a common support $\bar{\zeta}=\left\{\zeta_{1}, \zeta_{2}, \ldots, \zeta_{N}\right\}$, where $\zeta_{1}=1<\zeta_{2}<\ldots<\zeta_{N} \cdot{ }^{7}$ We first assume that governments can observe each other's political parameter and later comment on the static game under the assumption of private information.

We assume that governments maximize the sum of tariff revenues, consumer surplus and producer surplus in each of the markets: in the case of the import good, the valuation given to the latter is adjusted by the political economy parameter. ${ }^{8}$ Thus, the objective function of Home's government can be expressed as,

$$
W^{H}\left(p_{x}^{H}, p_{y}^{H}, p_{x}^{W}, p_{y}^{W}, \zeta^{H}\right)=W_{x}^{H}\left(p_{x}^{H}, p_{x}^{W}, \zeta^{H}\right)+W_{y}^{H}\left(p_{y}^{H}, p_{y}^{W}\right)
$$

where $W_{x}^{H}$ and $W_{y}^{H}$ represent welfare derived from the $x$ and $y$ markets, respectively. These are in turn defined by

$$
\begin{aligned}
W_{x}^{H}\left(p_{x}^{H}, p_{x}^{W}, \zeta^{H}\right) & =\int_{\hat{p}_{x}}^{\frac{\alpha}{\beta}} D_{x}^{H} d p_{x}+\zeta^{H} \cdot \lambda_{x}^{H}\left(p_{x}^{H}\right)+\left[p_{x}^{H}-p_{x}^{W}\right] M_{x}^{H}, \\
W_{y}^{H}\left(p_{y}^{H}, p_{y}^{W}\right) & =\int_{\hat{p}_{y}}^{\frac{\alpha}{\beta}} D_{y}^{H} d p_{y}+\lambda_{y}^{H}\left(p_{y}^{H}\right)-\left[p_{y}^{H}-p_{y}^{W}\right] E_{y}^{H},
\end{aligned}
$$

where $\lambda_{i}^{H}\left(p_{i}^{H}\right)$ denotes the profits of Home's producers of good $i \in\{x, y\}$ as a function of domestic

\footnotetext{
${ }^{7}$ The assumption that $\zeta$ is uniformly distributed is made only to simplify the exposition.

${ }^{8}$ Thus, we follow Baldwin (1987) in interpreting the weights on producer surplus that exceed unity as representing domestic political economy forces.
} 
prices, respectively, and - as was said earlier $-\zeta^{H}$ represents the political economy parameter of the government of Home. Note that the welfare functions as expressed above depend solely on the world and domestic prices of both goods and, ultimately, on the values of Home and Foreign's import tariffs and export subsidies. In the case of Foreign's government, its welfare functions are analogous to the ones depicted above with the difference that the corresponding political economy parameter $\left(\zeta^{F}\right)$ affects the weight given to producers of good $y$.

Assume first that both governments observe each other's political parameter and simultaneously set tariffs and subsidies so as to unilaterally maximize welfare. In other words, for given values of $\zeta^{H}$ and $\zeta^{F}$, the government of $j \in\{H, F\}$ solves

$$
\max _{\tau_{x}^{j}, \tau_{y}^{j}} W^{j}\left(p_{x}^{j}, p_{y}^{j}, p_{x}^{W}, p_{y}^{W}, \zeta^{j}\right)
$$

$>$ From Equation (6), the best response functions must satisfy the first order conditions

$$
W_{p_{i}^{W}}^{j} \frac{\partial p_{i}^{W}}{\partial \tau_{i}^{j}}+W_{p_{i}^{j}}^{j} \frac{\partial p_{i}^{j}}{\partial \tau_{i}^{j}}=0, \text { for } j \in\{H, F\} \text { and } i \in\{x, y\}
$$

Equation (7) reflects the well-known fact that trade policy influences welfare through its impact on the terms of trade and on domestic prices. For the importing government, an increase in tariffs has the following effects: it increases the domestic price of the good, redistributing wealth from consumers to producers while inducing a loss of surplus, and it has a favorable effect on the terms of trade. The higher the political economy parameter, the higher is the positive weight given to the redistributive effect and the higher will be the desired tariffs.

The Nash equilibria of the present model have been studied at length in the literature and are well understood. ${ }^{9}$ In order to assess their properties in terms of efficiency, we first characterize the properties of efficient tariffs. In order for pairs of tariffs $\left(\tau_{i}^{H}, \tau_{i}^{F}\right), i \in\{x, y\}$, to be efficient, it must be the case that they maximize the sum of Home and Foreign's welfare, i.e., they must be a solution to the following maximization problem:

$$
\max _{\tau_{i}^{H}, \tau_{i}^{F}} \sum_{j \in\{H, F\}} W^{j}\left(p_{x}^{j}, p_{y}^{j}, p_{x}^{W}, p_{y}^{W}, \zeta^{j}\right), \text { for } i \in\{x, y\}
$$

It is straightforward to show from Equation (8) that, in the present model, aggregate welfare depends only on the net tariffs in each market, i.e. on $\left(\tau_{i}^{H}-\tau_{i}^{F}\right)$ for $i \in\{x, y\}$. The way in which this total welfare is distributed among governments is determined by the precise values of the tariffs

\footnotetext{
${ }^{9}$ See, for example, Bagwell and Staiger (2001).
} 
and subsidies. We will focus on a particular pair of efficient tariffs and subsidies as our benchmark, which we call "politically-optimal" tariffs and denote by $\tau_{i}^{j^{*}}$ for $j \in\{H, F\}$ and $i \in\{x, y\}$. These are implicitly defined by the following first order conditions,

$$
W_{p_{i}^{j}}^{j} \frac{\partial p_{i}^{j}}{\partial \tau_{i}^{j}}=0, \text { for } j \in\{H, F\} \text { and } i \in\{x, y\} \text {. }
$$

Thus, politically-optimal tariffs are defined as the tariffs (and subsidies) that governments would choose if they internalized the externality generated by the terms-of-trade effect, being therefore lower (higher) than their Nash counterparts obtained from Equation (7).

Due to the lack of political economy considerations in the export market, the politically-optimal export subsidy in the present model is always zero. Regarding the import market, on the other hand, the politically-optimal tariff of country $j \in\{H, F\}$ is strictly positive for all values of $\zeta^{j}>1$, and it is increasing in $\zeta^{j}$. Thus, the net tariff that arises in the $x$ market from governments choosing their politically-optimal tariffs and subsidies is simply $\tau_{x}^{H^{*}}\left(\zeta^{H}\right)$, and all combinations $\left(\tau_{x}^{H}, \tau_{x}^{F}\right)$ for which $\tau_{x}^{H}-\tau_{x}^{F}=\tau_{x}^{H^{*}}\left(\zeta^{H}\right)$ deliver the same total welfare.

Before proceeding, it is worthwhile at this point to highlight one characteristic of welfare functions in our model. Since welfare depends directly on world and local prices, which are in turn determined solely by tariffs and subsidies, the welfare of Home and Foreign can ultimately be expressed as functions of the latter. This is the approach we take throughout the rest of the paper, and we therefore briefly state the properties of welfare functions so expressed. We can write the welfare of the government of $j$ as $W^{j}\left(\tau^{H}, \tau^{F}, \zeta^{j}\right)$, where $\tau^{H}=\left(\tau_{x}^{H}, \tau_{y}^{H}\right)$ and $\tau^{F}=\left(\tau_{x}^{F}, \tau_{y}^{F}\right)$. The support for $\zeta^{j}$ is chosen so that $W^{j}$ is twice continuously differentiable with respect to $\tau^{H}$ and $\tau^{F} .10$ Since we will always use politically-optimal tariffs as our benchmark, we will be concerned with efficient tariffs that lie below the reaction function (below the Nash tariffs). For these ranges of tariffs, it can be shown that welfare of a given government is increasing and concave in its import tariff and decreasing in its export subsidy. Also, it is always the case that the marginal impact of an increase in import tariffs on welfare is increasing in the realization of the political economy parameter.

We are now ready to characterize the Nash equilibria of the static model under full information. We do so in the following result, which closely follows Bagwell and Staiger (2001):

Result 1. In the static tariff game with full information,

\footnotetext{
${ }^{10}$ The support of $\zeta^{j}$ is relevant for this because, if the possible values of the parameter are too far apart, there are efficient equilibria with no trade: at this point, then, $W^{j}$ would clearly not be twice continuously differentiable with respect to the tariffs.
} 
1. There exists a unique Nash equilibrium with positive trade volume (this follows from the strict concavity of the welfare function).

2. In the aforementioned equilibrium, the Nash import tariff is positive while the Nash export subsidy is negative, and all tariffs are higher than their politically optimal values.

3. There also exists a continuum of autarky Nash equilibria. ${ }^{11}$

The previous result highlights a well-known conclusion of the strategic trade literature, by which Nash tariffs are inefficient due to governments' desire to overexploit them in order to affect the terms of trade in their favor. In this sense, both governments could benefit from a reciprocal reduction of tariffs and increase of subsidies, since such a change could leave the terms of trade constant while reducing everyone's domestic prices.

We now turn to the case in which governments cannot observe each other's political preferences. In this case, the game is assumed to be as follows: governments learn their 'types' at the beginning of each period, after which they set their tariffs and subsidies in a simultaneous fashion and trade takes place. In such a scenario, welfare functions are determined exactly as before, with the only difference that governments are uncertain about each other's preferences. Thus, they choose the tariffs and subsidies that maximize expected welfare. In particular, we define the welfare function of Home's government in the interim stage (i.e., after observing its own type, but not that of foreign) as

$$
W^{H}\left(\tau^{H}, \tau^{F}, \zeta^{H}\right)=W_{x}^{H}\left(\tau_{x}^{H}, \tau_{x}^{F}, \zeta^{H}\right)+\frac{1}{N} \sum_{\zeta^{F} \in \bar{\zeta}} W_{y}^{H}\left(\tau_{y}^{H}, \tau_{y}^{F}\left(\zeta^{F}\right)\right),
$$

while that of foreign takes an analogous form (with the obvious difference that welfare is deterministic in the $y$ market and random in the $x$ market). Note from Equation (10) that the Home government faces no uncertainty on the $x$ market, since Foreign has no private information regarding this good. In the $y$ market, however, Foreign's type will affect its tariff and - consequently - the world price of this good. Thus, in choosing its level of subsidy, Home maximizes expected welfare in the market for its export good.

It is easy to show that the equilibrium of the asymmetric information case involves the same kind of inefficiency that was previously described. This must indeed be the case, since the introduction of asymmetric information does not eliminate the terms-of-trade externality and - consequently governments have an incentive to set inefficiently high (low) import tariffs (export subsidies).

\footnotetext{
${ }^{11}$ To see this, imagine a situation in which import tariffs (export subsidies) are set so high (low) as to individually eliminate the exchange of goods between both countries. Any such situation is clearly a Nash equilibrium, since no country can induce trade by unilaterally lowering (raising) its tariff (subsidy).
} 
Lemma 1. The Nash equilibrium of the static game with asymmetric information entails suboptimally high (low) import tariffs (export subsidies).

Proof. This result stems directly from our previous analysis and the proof is therefore omitted.

Thus, the properties of the original equilibria are preserved under asymmetric information, entailing suboptimally high tariffs and a consequent loss of efficiency due to the existence of a terms-of-trade externality. We now analyze an infinitely repeated version of this game and study its equilibrium payoffs under different scenarios.

\section{The repeated model}

We maintain the assumption of two countries, Home and Foreign, whose governments are assumed to discount future welfare at rate $\delta$ where $0 \leq \delta<1$. Each period $t \in\{1,2, \ldots\}$, the government of $j \in\{H, F\}$ privately observes the realization of its political preference $\zeta_{t}^{j}$ : the realizations of both governments are independently drawn from a common, uniform distribution with finite support $\bar{\zeta}=\left\{\zeta_{1}, \zeta_{2}, \ldots, \zeta_{N}\right\}$, where $\zeta_{1}<\zeta_{2}<\ldots<\zeta_{N}$. Depending on the scenario considered, each government can set the level of one or more policy instruments.

We analyze this repeated game by using a mechanism design approach. ${ }^{12}$ To illustrate in a simple manner what this means, we consider a setting in which governments interact repeatedly and communicate with one another. Upon observing their political preferences at each point in time, each government makes an announcement regarding its realization. Governments observe each other's announcements and then set tariffs according to some pre-specified rule. We believe communication between governments before tariff-setting to be a realistic assumption, which in turn allows them to coordinate on the levels at which to set their policy instruments. ${ }^{13}$

Coordination in our repeated game is formally modelled as follows: at the beginning of each period $t \in\{1,2, \ldots\}$, both governments report their private signals to one another according to a reporting rule $\hat{\zeta}_{t}^{j}\left(\zeta_{t}^{j}\right): \bar{\zeta} \rightarrow \bar{\zeta}$, for $j \in\{H, F\}$. Once both reports $\left(\hat{\zeta}_{t}^{H}, \hat{\zeta}_{t}^{F}\right)$ have been made, each government must set its tariffs according to some pre-specified instruction rule by which they must abide. An instruction rule, denoted by $u_{t}=\left(u_{t}^{H}, u_{t}^{F}\right): \bar{\zeta}^{2} \rightarrow R^{2 n}$, is a mapping from announcements to policy instruments. If each government has $n$ available policy instruments, $R^{2 n}$ represents the policy space for both governments. Given this communication structure we model the behavior of governments as simply choosing a tariff rule, $\rho_{t}^{j}: \bar{\zeta}^{2} \times R^{n} \rightarrow R^{n}$ for $j \in\{H, F\}$, which maps their

\footnotetext{
${ }^{12}$ See, for example, Athey et al.(2004) and Athey and Bagwell (2001).

${ }^{13}$ Besides allowing for communication, we also require the existence of a randomization device that countries can use to correlate their actions whenever this is necessary. This assumption is standard in the repeated game literature.
} 
type, their report and the instruction rule into tariffs, subsidies or other policy instruments.

Communication history for the government of $j$ in period $t$ of the repeated game is the sequence of its reports and instructions in periods $1,2, \ldots, t-1$. Private history is the sequence of its private signals $\zeta_{t}^{j}$ in periods $1,2, \ldots, t-1$. Finally, public history in period $t$ is a sequence of instruction rules used at each point in time and the values of the policy instruments actually chosen by both governments in periods $1,2, \ldots, t-1$.

The strategy of government $j$, denoted by $\sigma^{j}$, is a pair of reporting and tariff rules $\left(\hat{\zeta}_{t}^{j}, \rho_{t}^{j}\right)$ for each period defined as a function of its communication and private histories and of the public history at that time. ${ }^{14}$ Define $\hat{\sigma}^{j}$ to be the honest and obedient strategy which selects truthful announcements and obedient tariff rules for all histories, i.e., the strategy by which a country always reports its true type and - having done that - sets its tariffs at the levels prescribed by the instruction rule. Let the coordination scheme $C$ denote the instruction rule that governments agree to follow ex-ante, as a function of communication and public histories. Then, the coordination scheme $C$ is said to be an equilibrium if the pair $\Sigma=\left(\hat{\sigma}^{H}, \hat{\sigma}^{F}\right)$ is a perfect public equilibrium of the repeated game, i.e., if $\hat{\sigma}^{j}$ is optimal against $\left(\hat{\sigma}^{j^{\prime}}, C\right)$ for $j, j^{\prime} \in\{H, F\}, j \neq j^{\prime}$, after any public and communication history of the game.

We will characterize equilibrium strategies by using the one-shot deviation property. ${ }^{15}$ These deviations, in turn, can be divided into two types which are usually called on- and off-schedule deviations. ${ }^{16}$ The latter refer to deviations that are observable, i.e., setting tariffs at a level different from the one indicated by the corresponding instruction rule given the communication and public history. These deviations are always assumed to trigger Nash reversion. On-schedule deviations, on the other hand, arise when governments misrepresent their type: obviously, these deviations are not observable. To control for these deviations we will make sure that on-schedule incentive compatibility constraints are locally satisfied, and then prove in each case that they are satisfied globally by the presence of a single-crossing property.

\section{Repeated model with many instruments}

The present section analyzes the equilibria of the repeated game in the presence of more than one instrument, namely, import tariffs and transfers or import tariffs and export subsidies. In such a setting, the instruction and tariff rules refer to all of the instruments involved: for example, in the

\footnotetext{
${ }^{14}$ In order to simplify the exposition, we henceforth drop the time subscript $t$ whenever doing so does not generate confusion.

${ }^{15}$ The one-shot deviation property is valid in our setup due to the boundedness of per-period payoffs and discounting.

${ }^{16}$ See Athey and Bagwell (2001).
} 
case of import tariffs and transfers, the instruction rule specifies a level for both instruments, and so does the tariff rule used by each country. The question addressed is whether there are efficient equilibria when each country controls more than one instrument.

In the presence of transfers, this question can be answered in a rather straightforward manner. The inefficiency of the model arises precisely because, if governments agree to apply the politicallyoptimal import tariffs associated to their reports, they both have an incentive to over-represent their type. The reason for this is that they stand to gain by altering the terms of trade in their favor and against their trading partner, and they do not consider the externality that they generate by doing so. Thus, any coordination scheme that leads governments to internalize this externality will suffice to achieve efficiency.

When transfers are feasible, the simplest of such schemes is one in which governments pay a transfer equal to the externality that is generated when they set tariffs at their politically-optimal levels. Such a scheme provides governments with the incentives to report their types truthfully, whereas Nash reversion provides them with the incentives to follow an obedient tariff rule. This efficiency result in the presence of transfers is fairly intuitive, and we therefore provide the proof in the Appendix.

Let $\hat{T}^{j}\left(\hat{\zeta}^{j}\right)$ denote the mapping from announcements to transfers that, by internalizing the terms-of-trade externality, achieves truthtelling when tariffs are set at their politically-optimal levels given announcements, i.e. $\tau^{j}=\tau^{j^{*}}\left(\hat{\zeta}^{j}\right)$ for $j \in\{H, F\}$. We obtain the following result:

Proposition 1. In the presence of transfers and import tariffs there exists a critical level of the discount factor $\hat{\delta}$, such that for all $\delta \geq \hat{\delta}$, an efficient coordination scheme $C$ characterized by instruction rules $\left(u_{t}^{H}, u_{t}^{F}\right)=\left(\left(\tau_{x}^{H^{*}}\left(\hat{\zeta}_{t}^{H}\right), \hat{T}^{H}\left(\hat{\zeta}_{t}^{H}\right)\right),\left(\left(\tau_{y}^{F^{*}}\left(\hat{\zeta}_{t}^{F}\right), \hat{T}^{F}\left(\hat{\zeta}_{t}^{F}\right)\right)\right.\right.$ for all $t \in\{1,2, \ldots\}$ can be supported as a perfect public equilibrium of the repeated trade model.

Proof. See Appendix.

Note that the possibility of resorting to these two instruments allows governments to achieve efficiency within all periods by transferring welfare between them. In other words, there is no need to resort to the manipulation of future payoffs, because the availability of sufficiently many instruments allows for the achievement of efficiency and incentive compatibility on a period-byperiod basis. However, the use of transfers among countries as direct compensation for tariff increases is not observed in practice.

We consider next the effects of eliminating transfers as policy instruments while allowing governments to resort to export subsidies instead. Thus, the instruction and tariff rules will now refer 
to the levels of import tariffs and export subsidies. ${ }^{17}$ In this case, the interim welfare of Home's government is given by

$$
W^{H}\left(\sigma^{H}, C, \zeta^{H}\right)=W_{x}^{H}\left(\tau_{x}^{H}\left(\hat{\zeta}^{H}\right), \tau_{x}^{F}\left(\hat{\zeta}^{H}\right), \zeta^{H}\right)+\frac{1}{N} \sum_{\zeta^{F} \in \bar{\zeta}} W_{y}^{H}\left(\tau_{y}^{H}\left(\zeta^{F}\right), \tau_{y}^{F}\left(\zeta^{F}\right)\right)+v
$$

whereas the welfare of Foreign's government can be defined analogously. Since a government's announcement affects only the current welfare that it derives from the import market, Home's on-schedule incentive compatibility constraint reduces to

$$
W_{x}^{H}\left(\tau_{x}^{H}\left(\zeta^{H}\right), \tau_{x}^{F}\left(\zeta^{H}\right), \zeta^{H}\right) \geq W_{x}^{H}\left(\tau_{x}^{H}\left(\hat{\zeta}^{H}\right), \tau_{x}^{F}\left(\hat{\zeta}^{H}\right), \zeta^{H}\right)
$$

for all $\zeta^{H}, \hat{\zeta}^{H} \in \bar{\zeta}$. Suppose that the world price is set at some prespecified level $\bar{p}_{x}^{W}$. In order for the previous inequality to be satisfied for any realization of $\zeta^{H}$, it suffices that any effects of Home's announcements on the terms of trade are offset by a corresponding adjustment in the export subsidy of Foreign. In other words, any tariff-subsidy instruction rule satisfying

$$
\begin{aligned}
\tau_{x}^{H}\left(\zeta^{H}\right)-\tau_{x}^{F}\left(\zeta^{H}\right) & =\tau_{x}^{H^{*}}\left(\zeta^{H}\right), \\
p_{x}^{W}\left(\tau_{x}^{H}\left(\zeta^{H}\right), \tau_{x}^{F}\left(\zeta^{H}\right)\right) & =\bar{p}_{x}^{W},
\end{aligned}
$$

for all $\zeta^{H} \in \bar{\zeta}$ will support truthtelling and the setting of efficient tariffs by Home. An analogous condition in the $y$ market holds for the case of Foreign. The intuition is essentially the same as when governments resorted to transfers: the difference is that, whereas previously governments internalized the externality they generated by attaching a payment to their announcement, here they are led to do so by attaching a decrease in its trading partner's subsidy to their announcement. Proposition 2 states the formal result and we refer the interested reader to the Appendix. It suffices to stress here that the presence of export subsidies could in principle help to achieve efficiency on a per-period basis. However, the use of this instrument is currently restricted under the GATT/WTO system. $^{18,19}$

Proposition 2. ${ }^{20}$ In the presence of export subsidies and import tariffs there exists a critical level

\footnotetext{
${ }^{17}$ Note that a government's preferred level of export subsidies is not affected by the realization of its own political economy parameter.

${ }^{18}$ In this regard, Article 3 of the Agreement on Subsidies and Countervailing Measures explicitly prohibits subsidies which are "contingent, in law or in fact, whether solely or as one of several other conditions, upon export performance."

${ }^{19}$ Additionally, note that a coordination scheme like the one described above will repeatedly entail the use of export and/or import subsidies: although in our model countries are not assumed to be liquidity constrained, the latter would seem a priori to be a justifiable concern in considering a real-world implementation of the scheme.

${ }^{20}$ One of the referees made an interesting point regarding the critical level of the discount factors in Propositions 1 and 2. Efficient and incentive compatible combinations of import tariffs and export subsidies (taxes) can be thought
} 
of the discount factor $\hat{\delta}$, such that for all $\delta \geq \hat{\delta}$, an efficient coordination scheme $C$ characterized by instruction rules $\left(u_{t}^{H}, u_{t}^{F}\right)=\left(\left(\hat{\tau}_{x}^{H}\left(\hat{\zeta}_{t}^{H}\right), \hat{\tau}_{y}^{H}\left(\hat{\zeta}_{t}^{F}\right)\right),\left(\left(\hat{\tau}_{x}^{F}\left(\zeta_{t}^{H}\right), \hat{\tau}_{y}^{F}\left(\hat{\zeta}_{t}^{F}\right)\right)\right)\right.$ for all $t \in\{1,2, \ldots\}$ can be supported as a perfect public equilibrium of the repeated trade model.

Proof. See Appendix.

Thus, of the two additional instruments that would allow for the implementation of an efficient allocation - transfers and export subsidies - none of them are readily available to governments interacting in the existing world trade system. In the next section, we consequently analyze the efficiency of equilibria when import tariffs are the only policy instruments to which governments can resort.

\section{Repeated model with one instrument}

Once it is assumed that governments can only resort to import tariffs at each point in time, a difficulty arises. Specifically, import tariffs at each point in time must now fulfill a double role: they must achieve efficiency while at the same time providing incentives for truthtelling. The main result of this section is that, in order for efficiency to be attained in such a setting, higher tariffs from any one government today must be associated to higher tariffs from the other government in the future. Hence, retaliation is necessary.

\subsection{Reciprocal equilibrium}

Consider first the case in which incentive compatibility is achieved in the following manner: whenever a government raises its tariff, its trading partner does the same. We refer to any such equilibrium as a reciprocal equilibrium. Note that a reciprocal equilibrium implements a reciprocal tariff withdrawal scheme of the type featured in the GATT escape clause mechanism, in which a country could raise its tariff but this would give its trading partner the simultaneous right to raise its tariff in a reciprocal fashion.

In a reciprocal equilibrium, incentives for truthtelling are provided by letting each government's announcement influence the contemporaneous tariff of its trading partner. To be more precise,

of as involving an indirect transfer. In the equilibrium of Proposition 2, the export subsidy (tax) is not controlled by the importing country. Hence, its gains from deviating at any given point are lower than what they would be in the equilibrium of Proposition 1, which entails incentive compatible combinations of import tariffs and direct transfers: indeed, a deviating country in such an equilibrium would not only gain by raising its tariff, but it would also do so by avoiding the corresponding transfer. Consequently, an equilibrium based on combinations of import tariffs and direct transfers may involve a higher incentive to deviate off-schedule, thereby requiring higher levels of patience than equilibria based on combinations of import tariffs and export subsidies or taxes. For a related discussion on this point, see Park (2000). 
consider an equilibrium in which, at each point in time, both governments announce their types and set their tariffs according to some pre-specified instruction rule that relates each tariff to both announcements. In such a way, whenever a country announces that it has a high preference for protection in its import market in a given period, it increases the expected tariff that its trading partner will set on the other market. As before, observable deviations, in which governments set tariffs different from the ones that had been agreed upon for a given set of announcements, are dealt with through Nash reversion. Let $\tau^{j, r}\left(\hat{\zeta}^{H}, \hat{\zeta}^{F}\right)$ denote the equilibrium tariff that is set by the government of country $j \in\{H, F\}$ as a function of announcements in the best (symmetric) reciprocal equilibrium, and let $W^{r}$ denote the expected average welfare of governments in such an equilibrium. That is, out of the set of all reciprocal equilibria, setting tariffs according to $\tau^{j, r}$ maximizes expected joint welfare.

We argue that such an equilibrium must always yield lower welfare than the unique efficient allocation, in which governments set their import tariffs at their politically-optimal levels at each point in time. First, note that the efficient allocation can never be an equilibrium in the current setup. The reason is simple. When governments can only resort to their import tariffs, it is efficient for each country's tariff to depend only on the realization of its political economy parameter: however, since the latter is not observed, governments have an incentive to report high types so as to set higher tariffs at equilibrium. If truthtelling is to be induced, then, incentives must somehow be provided and this will come at an efficiency loss. We show this intuition formally in the following proposition $^{21}$ :

Proposition 3. Any reciprocal equilibrium is necessarily inefficient.

Proof. In a reciprocal equilibrium, Home's interim welfare from announcing $\hat{\zeta}^{H}$ when its true type is $\zeta^{H}$ can be expressed as

$$
W^{H}\left(\sigma^{H}, C, \hat{\zeta}^{H}, \zeta^{H}\right)=\frac{1}{N} \sum_{\zeta^{F} \in \bar{\zeta}}\left(W_{x}^{H}\left(\tau_{x}^{H}\left(\hat{\zeta}^{H}, \zeta^{F}\right), \zeta^{H}\right)+W_{y}^{H}\left(\tau_{y}^{F}\left(\hat{\zeta}^{H}, \zeta^{F}\right)\right)\right)+v
$$

where $v$ is the continuation payoff, independent of the announcement(s). Since a government's announcement affects only the current welfare that it derives from its import market, Home's on-schedule incentive compatibility constraint reduces to

$$
W^{H}\left(\sigma^{H}, C, \zeta^{H}, \zeta^{H}\right) \geqslant W^{H}\left(\sigma^{H}, C, \hat{\zeta}^{H}, \zeta^{H}\right),
$$

\footnotetext{
${ }^{21}$ In fact, one can easily prove a stronger condition that states that any reciprocal equilibrium is necessarily bounded away from efficiency.
} 
for all $\zeta^{H}, \hat{\zeta}^{H} \in \bar{\zeta}$. As we have previously observed, though, Home's politically optimal tariffs depend only on its own political parameter, i.e. $\tau_{x}^{H^{*}}\left(\zeta^{H}\right)$. Hence, if Home sets its tariffs at their politically optimal levels the previous inequality reduces to

$$
W_{x}^{H}\left(\tau_{x}^{H^{*}}\left(\zeta^{H}\right), \zeta^{H}\right) \geqslant W_{x}^{H}\left(\tau_{x}^{H}\left(\hat{\zeta}^{H}\right), \zeta^{H}\right) \text { for all } \zeta^{H}, \hat{\zeta}^{H} \in \bar{\zeta}
$$

This inequality can only hold if Home unilaterally maximizes welfare by choosing the politically optimal tariffs, which cannot be true by definition. The same arguments holds for Foreign.

\subsection{Role of retaliation}

As opposed to the reciprocal equilibrium that we analyzed above, there are two ways in which retaliation helps to enhance efficiency. The first is that, differently from reciprocity, retaliation as we have defined it implies that higher tariffs today by any one country decrease its expected welfare in future periods. By spreading incentives out across time, then, retaliation may reduce the cost of providing them. This point is related to the results of Riezman (1991) in a setting in which trade policy is unobservable: by applying the results of Green and Porter (1984), he showed how appropriate trigger strategies could be used to sustain some degree of cooperation. Although they are sometimes useful to enhance cooperation, trade wars in Riezman's setting cannot sustain efficiency. The reason is that Riezman focuses on symmetric equilibria in which high tariffs by any one country today increase the likelihood of symmetric trade wars in the future, in which both countries are punished. Restricting the analysis to symmetric equilibria, as we now argue, limits the ability of retaliation to enhance efficiency through a second channel: namely, by introducing asymmetry in future payoffs ${ }^{22}$.

In symmetric public perfect equilibria, when the public outcome observed by players is consistent with deviations, all players need to be punished even if no deviation has actually taken place. This necessarily generates a loss of efficiency. ${ }^{23}$ If we allow for asymmetric continuation payoffs, on the other hand, when the public outcome is consistent with deviation by any one player, this player can be 'punished' while others are 'rewarded'. Hence, incentive compatibility can in principle be achieved without losing overall welfare, simply by redistributing it differently across players. ${ }^{24}$

\footnotetext{
${ }^{22}$ Hungerford (1991) allowed for asymmetric equilibria in a setting very similar to Riezmann's: his focus, though, was not on the efficiency properties of equilibria, but rather on whether free trade was attainable in equilibrium.

${ }^{23}$ The reciprocal equilibria considered previously are a special case of symmetric equilibria, in the sense that the continuation payoffs are constant and equal to the stage-game payoffs of the reciprocal strategies.

${ }^{24}$ In technical terms, this idea is expressed by saying that a profile of strategies is enforceable or incentive compatible with respect to hyperplanes. This means that the continuation payoffs of both governments add up to a constant, so that future welfare can be transferred between them without affecting total welfare (i.e., in the two-country case, this means that continuation payoffs lie on a straight line with a slope of -1). This property is not satisfied by
} 
If asymmetric public perfect equilibria can outperform symmetric equilibria, how reasonable is it focus on the latter? In games with private information, it is natural to think that players will coordinate their actions on public or observable signals. In general, one could think of environments in which it is not possible to extract the individual actions from the observed public signal. In these cases, symmetric equilibria seem reasonable. In our trade setting, though, the public signal is simply the set of announced preferences for protection by all governments. Clearly, announcements made by different governments are perfectly distinguishable from one another, in which case it seems restrictive to limit the analysis to symmetric equilibria.

\subsubsection{An intuitive mechanism of welfare-enhancing retaliation}

We now illustrate in a very simple, closed-form manner the way in which the introduction of retaliation can increase welfare relative to the best reciprocal equilibrium. Before stating and proving the proposition we first provide the intuition of our argument. Suppose that we start with the best reciprocal equilibrium that generates expected per period welfare $W^{r}$. Then, there is an asymmetric public perfect equilibrium that involves some degree of retaliation and that does strictly better in terms of welfare. In such an equilibrium, governments at each point in time either; (a) set their tariffs at the politically-optimal level, in line with their announcements, or they; (b) play an asymmetric perturbation of the best reciprocal equilibrium. In case (b), incentive compatibility is achieved by the very definition of a reciprocal equilibrium. In case (a), incentive compatibility is obtained by letting announcements determine the probability of being punished next period. We will thus show that the introduction of asymmetry makes it possible for governments to enhance their cooperation, so that retaliation is welfare enhancing. ${ }^{25}$

To show this result formally in our model, we introduce one modification throughout this section: in order to obtain clear closed-form solutions, we assume a continuum of types. ${ }^{26}$ Hence, governments are assumed to draw a political preference parameter from a continuous distribution with support $\bar{\zeta}=\left[\zeta_{1}, \zeta_{N}\right]$ and uniform density $g$.

Proposition 4. Suppose that political preference parameters are drawn from a continuous distribution with support $\bar{\zeta}=\left[\zeta_{1}, \zeta_{N}\right]$ and uniform density $g$ and that the set of payoffs generated by reciprocal equilibria is smooth. Define $W^{r}$ to be the expected per period payoff of the best reciprocal

equilibrium strategies in symmetric equilibria, in which the continuation payoffs of all players need to decrease with some probability in order to achieve incentive compatibility.

${ }^{25}$ It is worthwile to note that a similar result would be obtained if we would slightly perturb symmetric "trade war" equilibria studied in Riezmann (1991). That is, introducing retaliation on top of symmetric trade wars can enhance cooperation.

${ }^{26}$ By working with a continuum of types, we can invoke differentiability in order to characterize a closed form solution. 
equilibrium. Then there exists an asymmetric (retaliatory) perfect public equilibrium of the repeated tariff game with expected period payoffs $v$, such that $v>W^{r}$.

\section{Proof. Step 1. Perturbing the best reciprocal equilibrium.}

If the set of expected payoffs generated by reciprocal equilibria is smooth, then equilibrium tariffs in the best reciprocal equilibrium $\tau^{j, r}$ for $j \in\{H, F\}$ can be locally perturbed to introduce asymmetry in payoffs without affecting joint welfare. ${ }^{27}$ Such a perturbation is characterized by a pair of tariff functions denoted by $\tau^{P}\left(\hat{\zeta}^{H}, \hat{\zeta}^{F}\right)$ and $\tau^{R}\left(\hat{\zeta}^{H}, \hat{\zeta}^{F}\right)$ such that

$$
\tau^{P}\left(\hat{\zeta}^{H}, \hat{\zeta}^{F}\right) \leq \tau^{j, r}\left(\hat{\zeta}^{H}, \hat{\zeta}^{F}\right) \leq \tau^{R}\left(\hat{\zeta}^{H}, \hat{\zeta}^{F}\right) \text { for all } \hat{\zeta}^{H}, \hat{\zeta}^{F} \in \bar{\zeta} \text { and } j \in\{H, F\}
$$

In this perturbation, one government is "rewarded", sets tariffs according to $\tau^{R}\left(\hat{\zeta}^{H}, \hat{\zeta}^{F}\right)$, and receives per period expected welfare denoted by $W^{R}$. The other government is "punished", sets tariffs according to $\tau^{P}\left(\hat{\zeta}^{H}, \hat{\zeta}^{F}\right)$, and receives per period expected welfare denoted by $W^{P}$. Keeping this in mind, we define a perturbation $\tau^{r}(\varepsilon)=\left\{\tau^{R}\left(\hat{\zeta}^{H}, \hat{\zeta}^{F}\right), \tau^{P}\left(\hat{\zeta}^{H}, \hat{\zeta}^{F}\right)\right\}$ as the profile of tariffs that constitute an asymmetric reciprocal equilibrium while satisfying

$$
\begin{aligned}
W^{R}\left(\tau^{r}(\varepsilon)\right)-W^{P}\left(\tau^{r}(\varepsilon)\right) & =\varepsilon \\
\frac{W^{R}\left(\tau^{r}(\varepsilon)\right)+W^{P}\left(\tau^{r}(\varepsilon)\right)}{2} & \approx W^{r} \text { for } \varepsilon \approx 0 .
\end{aligned}
$$

\section{Step 2. Retaliatory coordination scheme}

Assume governments adhere ex-ante to the following coordination scheme. First of all, they will cooperate with one another as long as no one triggers Nash reversion by deviating in an observable manner. While cooperating, in turn, countries can be either in a punishment phase or in a reward phase: which country starts in which phase is chosen at random before the game starts. In each period under cooperation, there can be two possible scenarios. With some probability $1-e$, governments find themselves in an asymmetric scenario in which $\tau^{r}(\varepsilon)$ is used in favor of the country that is in the reward phase. With probability $e$, on the other hand, governments find themselves in an efficient scenario in which they announce their preferences and set tariffs according to the politically-optimal rule. In this scenario, incentives for truthtelling need to be provided. This will be done by letting announcements induce a probability of switching from the punishment to the reward phase and vice-versa. All things equal, then, by increasing (decreasing) its announcement in the efficient scenario, a government in the reward (punishment) phase increases the probability of switching to the punishment (reward) phase. Given the announcements, we use $\pi\left(\hat{\zeta}^{H}, \hat{\zeta}^{F}\right)$ to

\footnotetext{
${ }^{27}$ This assumption is made to simplify the mechanism. Our general argument (see Section 5.2.2.) does not depend on it.
} 
denote the probability that a government in the reward state switches to the punishment state. The probability is symmetric for the government in the punishment state and denotes the likelihood of moving to the reward state.

\section{Step 3. Existence of an equilibrium of the retaliatory coordination scheme}

In order to establish the existence of an equilibrium and to analyze its welfare properties, we formulate the decision problem of governments in a recursive fashion and solve for incentive compatibility. Let $v^{R}$ and $v^{P}$ denote, respectively, the average payoffs that a government obtains from the coordination scheme in the reward and the punishment states. Additionally, let $\bar{W}^{*}$ denote the average expected payoff that a government obtains in the efficient phase and let $\bar{\pi}$ denote the expected transition probability. Then, $v^{R}$ and $v^{P}$ must satisfy

$$
\begin{aligned}
v^{R} & =(1-\delta)\left[e \bar{W}^{*}+(1-e) W^{R}\right]+\delta\left[e\left(\bar{\pi} v^{P}+(1-\bar{\pi}) v^{R}\right)+(1-e) v^{R}\right] \\
v^{P} & =(1-\delta)\left[e \bar{W}^{*}+(1-e) W^{P}\right]+\delta\left[e\left(\bar{\pi} v^{R}+(1-\bar{\pi}) v^{P}\right)+(1-e) v^{P}\right]
\end{aligned}
$$

Note that $\bar{\pi}$ must be a probability while satisfying the on-schedule incentive compatibility constraint, since it must induce truthtelling during the efficient phase. Assuming that Home is in the reward phase, this latter requirement implies that ${ }^{28}$

$$
\left.\frac{\partial\left[\int_{\zeta 1}^{\zeta_{N}} \pi\left(\hat{\zeta}^{H}, \zeta^{F}\right) g\left(\zeta^{F}\right) d \zeta^{F}\right]}{\partial \hat{\zeta}^{H}}\right|_{\hat{\zeta}^{H}=\zeta^{H}}=\frac{(1-\delta)}{\delta\left(v^{R}-v^{P}\right)} \cdot \frac{\partial W^{*}\left(\zeta^{H}\right)}{\partial \zeta^{H}}
$$

where $W^{*}\left(\zeta^{H}\right)$ denotes the interim welfare of Home in the efficient phase, or

$$
W^{*}\left(\zeta^{H}\right)=W_{x}^{H}\left(\tau_{x}^{H^{*}}\left(\zeta^{H}\right), \zeta^{H}\right)+\int_{\zeta 1}^{\zeta_{N}} W_{y}^{H}\left(\tau_{y}^{F^{*}}\left(\zeta^{F}\right)\right) \cdot g\left(\zeta^{F}\right) \cdot d \zeta^{F}
$$

Expression (20) provides the way in which $\pi$ must respond to announcements in order to guarantee incentive compatibility, and it can be integrated to yield

$$
\pi\left(\hat{\zeta}^{H}, \hat{\zeta}^{F}\right)=\frac{1}{2}+\frac{(1-\delta)}{\delta\left(v^{R}-v^{P}\right)}\left[W^{*}\left(\hat{\zeta}^{H}\right)-W^{*}\left(\hat{\zeta}^{F}\right)\right] .
$$

Rewriting $v^{R}-v^{P}$ from (18) and (19), and replacing in (21):

$$
\pi\left(\hat{\zeta}^{H}, \hat{\zeta}^{F}\right)=\frac{1}{2}+\frac{1-\delta(1-e)}{\delta(1-e)\left(W^{R}-W^{P}\right)}\left[W^{*}\left(\hat{\zeta}^{H}\right)-W^{*}\left(\hat{\zeta}^{F}\right)\right]
$$

\footnotetext{
${ }^{28}$ It is only necessary to check that incentive compatibility holds locally. If this is the case, global incentive compatibility follows from the single-crossing property.
} 
This expression for $\pi$ is consistent with the recursive formulation of the problem and guarantees incentive compatibility. It only remains to be verified that $\pi$ as defined above is in fact a probability, so that our coordination scheme has an equilibrium. To do so, normalize $\pi\left(\zeta_{N}, \zeta_{1}\right)=1$ and let $\Delta$ denote the difference $W^{*}\left(\zeta_{N}\right)-W^{*}\left(\zeta_{1}\right)$. Then, the coordination scheme has an equilibrium if and only if the probability of the efficient scenario is given by

$$
e(\delta, \varepsilon)=\frac{\delta \varepsilon-(1-\delta) 2 \Delta}{\delta(\varepsilon+2 \Delta)} \geq 0
$$

which is strictly increasing in payoff asymmetry $\varepsilon$. Note that, for any level of asymmetry $\varepsilon>0$, there exists a critical level of patience denoted by $\delta_{\varepsilon}$ such that $e(\delta, \varepsilon) \geq 0$ for all $\delta \geq \delta_{\varepsilon}$.

\section{Step 4 Local improvement}

We are now ready to show that our coordination scheme can deliver a payoff strictly greater than that of the best reciprocal equilibrium $W^{r}$. It is worthwhile to remember that, for $\varepsilon \approx 0$, $W^{P}+W^{R} \approx 2 W^{r}$. Total expected welfare from the coordination scheme given an $\varepsilon$ level of asymmetry and assuming $\delta>\delta_{\varepsilon}$ is therefore given by: ${ }^{29}$

$$
v(\varepsilon)=\frac{v^{R}+v^{P}}{2}=e(\delta, \varepsilon) \cdot \bar{W}^{*}+(1-e(\delta, \varepsilon)) \cdot\left(\frac{W^{R}+W^{P}}{2}\right) .
$$

Since we want to compare this scheme with the reciprocal equilibrium $(\varepsilon=0)$, we evaluate the expected payoffs of the coordination scheme at the limit $(\varepsilon \rightarrow 0$ and $\delta \rightarrow 1)$ and analyze the effects of introducing asymmetry. Formally,

$$
\begin{aligned}
{\left.\frac{d v}{d \varepsilon}\right|_{\varepsilon=0}}=\frac{\partial e(1,0)}{\partial \varepsilon}\left[\bar{W}^{*}-\left(\frac{W^{R}+W^{P}}{2}\right)\right]+{\frac{\partial\left(\frac{W^{R}+W^{P}}{2}\right)}{\partial \varepsilon}}_{\mid \varepsilon=0}(1-e(1,0)) \\
=\frac{1}{2 \Delta}\left[\bar{W}^{*}-W^{r}\right]>0 .
\end{aligned}
$$

As can be seen from Equation (23), the introduction of asymmetry in the best reciprocal equilibrium is welfare enhancing. The intuition behind this result is that locally, asymmetry has no effect on joint expected welfare but it provides incentives for truthtelling during the efficient scenario.

Inequality (23) is important because it shows that the result is not a local improvement around $\varepsilon=0$. In fact there exists an optimal level of asymmetry (or retaliation), that maximizes the welfare governments obtain from the trade agreements using the coordination mechanism.

\footnotetext{
${ }^{29}$ Note that $\delta_{\varepsilon} \rightarrow 1$ as $\varepsilon \rightarrow 0$. This is natural since, given arbitrarily small levels of asymmetry, arbitrarily high degrees of patience are required for incentive compatibility.
} 
Corollary 1. Given the coordination mechanism, there exists an optimal level of asymmetry, $\varepsilon^{*}$, which is strictly bounded away from $\varepsilon=0$.

Proof. This follows immediately from inequality (23). Since $\left.\frac{d v}{d \varepsilon}\right|_{\varepsilon=0}>0$, there must be some strictly positive level of asymmetry, $\varepsilon^{*}=W^{R}-W^{P}>0$, that maximizes the cooperation between the governments generated by such a coordination scheme.

\subsubsection{General result on retaliation and efficiency}

The previous mechanism has sought to show in an intuitive, closed-form manner, the way in which retaliation can be useful to enhance welfare beyond what reciprocity can yield. Nonetheless, the equilibrium payoffs of the mechanism are still bounded away from efficiency. We now argue that, not only can the introduction of some retaliation be welfare enhancing in our model, but it is also necessary to achieve efficiency.

Our result is derived immediately from the folk theorem for repeated games with imperfect information obtained by Fudenberg et al. (1994, henceforth FLM). Their result translated to our framework is that, in this class of games, all payoffs higher than those of autarky can be sustained as a perfect public equilibrium when governments become arbitrarily patient. In particular, this implies that efficient cooperation can be attained in equilibrium. ${ }^{30}$

As our previous discussion suggests, asymmetric public perfect equilibria play a very important role in the possibility of achieving efficient cooperation. Technically, efficiency is possible in games in which players are privately informed about their types whenever the public outcome of the game makes it possible to distinguish, statistically, individual deviations by any one player. More precisely, it is required that the public outcome has as many independent components as there are players, and that the actions of each player affect only one of these components.

This result translates very clearly to games of communication like our repeated trade model. In our setting, governments announce to each other their preference for protection at each point in time: the public outcome that is observed by all is therefore the profile of announcements made by both governments. Since announcements made by different governments are distinguishable from one another, the environment has a product structure. ${ }^{31}$ In such a scenario, efficiency is possible

\footnotetext{
${ }^{30}$ This result actually says that asymptotic efficiency can be reached. As the patience of governments increases, it becomes possible to sustain equilibrium payoffs closer to those of efficient cooperation. In the limit (i.e., $\delta \rightarrow 1$ ) efficient cooperation is obtained.

${ }^{31}$ In other words, the possibility of redistributing future welfare between governments can only be of help if they can be held responsible individually (in a statistical manner) for their actions. When, after observing some public outcome, it cannot be established statistically whether one government or another is most likely to have deviated, asymmetric continuation payoffs cannot be used in order to induce truthtelling because it will not be possible to determine who should receive a lower or a higher continuation payoff.
} 
and requires asymmetric continuation payoffs. Given that governments can only resort to import tariffs, asymmetric retaliation is then necessary for efficiency.

To make the argument formally, we invoke the folk theorem for repeated games of private information, which applies exactly to our game as formally described in Section 3. We remind the reader that a coordination scheme $C$ is defined as the set of instruction rules that governments agree to follow ex-ante, as a function of communication and public histories. The coordination scheme $C$ is an equilibrium if the pair $\Sigma=\left(\hat{\sigma}_{C}^{H}, \hat{\sigma}_{C}^{F}\right)$ is a perfect public equilibrium of the repeated game, i.e., if the truthful and obedient announcement and tariff rule $\hat{\sigma}_{C}^{j}$ is optimal against $\left(\hat{\sigma}_{C}^{j}, C\right)$ for $j, j^{\prime} \in\{H, F\}, j \neq j^{\prime}$ after any public and communication history of the game.

Let $W(u)$ be the average payoffs of the static tariff game when players are truthful and obediently follow instruction rule $u$. It is said that the coordination scheme $C$ implements instruction rule $u$ if it is an equilibrium and yields expected average discounted payoffs equal to $W(u)$. The following adaptation of FLM's theorem to our model then holds:

Theorem 1. Fix an instruction rule $u$ and let $\sigma^{N}$ denote a profile of strategies that constitute a Nash equilibrium of the corresponding static tariff game. Suppose that the distribution of types is independent across countries. Let $V^{0}$ be the set formed by the convex hull of $W\left(\sigma^{N}\right)$ and the feasible points that Pareto dominate it. If $V^{0}$ has a non-empty interior, then all payoff vectors in $V^{0}$ can be approximated by equilibrium coordination schemes for discount factors close enough to 1. In particular, if $u=u^{*}: \zeta^{2} \rightarrow\left(\tau^{H^{*}}\left(\hat{\zeta}^{H}\right), \tau^{F^{*}}\left(\hat{\zeta}^{F}\right)\right)$, then there exists an equilibrium coordination scheme $C$ that (approximately) implements u for all $\delta$ sufficiently close to 1.

Proof. See FLM (1994), p. 1030.

Theorem 1 states that all payoff profiles that Pareto dominate those corresponding to a Nash equilibrium of the static tariff game can be attained as equilibrium payoffs of the repeated game if governments are sufficiently patient. In particular, the coordination scheme that implements the politically-optimal tariff rule can be supported as an equilibrium as governments become arbitrarily patient. ${ }^{32}$ We wish to stress again that this result is based on the fact that the structure of the tariff game is such that governments can distinguish each others' actions. This feature is what ultimately allows them to redistribute future welfare according to present actions, and to do so with a minimal loss of joint welfare as $\delta \rightarrow 1$.

\footnotetext{
${ }^{32}$ Theorem 1 says nothing regarding the characterization of the actual coordination schemes that implement a particular instruction rule. Our mechanism developed in the previous section provided one way to improve upon the best reciprocal equilibrium.
} 


\section{Retaliation and the use of WTO trade remedies}

We have shown that, in our repeated trade model with private information, retaliation is a necessary feature of any equilibrium that attains (asymptotic) efficiency. We now turn to the evidence on the use of WTO trade remedies and interpret them in light of our theoretical results.

Trade relationships entail repeated interaction among different governments. There is ample evidence that trade policy is shaped by political lobbying, and it seems reasonable to assume that governments hold some degree of private information regarding their true preferences. ${ }^{33} \mathrm{In}$ this context, governments benefit from having some degree of flexibility in the use of their trade instruments. At the same time, though, this flexibility must be subject to some type of control since otherwise governments have an incentive to abuse it. How can this control be implemented in practice? As we have said earlier, an adequate system of transfers or export subsidies could work, but transfers are rarely used and the use of subsidies is restricted by WTO/GATT. Within the context of the WTO, this leaves two main channels to control potential deviations, namely; a) to challenge them in the context of the Dispute Settlement Understanding (DSU) ${ }^{34}$, or; b) to retaliate directly through the application of trade remedies, such as AD or safeguards.

\subsection{Evidence on $\mathrm{AD}$ and safeguards}

We first focus on the evidence regarding the use of trade remedies, and will later comment on the DSU. The first striking fact regarding the use of trade remedies is the proliferation of AD relative to safeguards. Between 1980 and 1998, the annual number of AD complaints filed or reported to GATT increased from 69 to $246 .^{35}$ Moreover, the total number of countries using AD tripled within this period. In contrast, the GATT's safeguards provision of Article XIX was used only 150 times between 1947 and 1994, and has remained relatively unused even though the Agreement on Safeguards of 1994 seemed to make these measures more appealing. ${ }^{36}$

What accounts for the difference between these two types of trade remedies? Since countries apparently find $\mathrm{AD}$ measures useful in a way that safeguards are not, answering this question

\footnotetext{
${ }^{33}$ In particular, the use of AD seems to be significantly influenced by political considerations. Hansen (1990), Moore (1992) and Hansen and Prusa (1997) provide evidence for the United States. Francois and Niels (2004) do so for the case of Mexico.

${ }^{34}$ The DSU sets out rules and procedures for resolving disputes that arise between WTO members concerning the interpretation and application of the WTO Agreement. These procedures entail consultations between the disputing countries and, in case no agreement is reached, the potential establishment of a dispute settlement panel to decide on the dispute. If it is determined that a country is in violation of its WTO obligations, the procedure is as follows: a) this country is given a "reasonable period of time" to bring itself into conformity; b) if it fails to do so whithin that period, the violating country can offer adequate compensation to the complaining country; c) the complaining country may retaliate if authorized by the dispute settlement panel.

${ }^{35}$ See Prusa (2001).

${ }^{36}$ Bown (2002) states that only 20 safeguard measures were undertaken between 1995 and 200, whereas 333 definitive AD measures were imposed between 1995 and 1997 alone.
} 
requires an understanding of the motivations underlying the use of $\mathrm{AD}$. The traditional motivation behind $\mathrm{AD}$ is the existence of dumped imports, goods sold either at a price below the one in the exporter's domestic market or at a price below his costs of production. ${ }^{37}$ An alternative explanation, consistent with our theoretical model, is that the use of AD is influenced by strategic considerations. There is a wide body of empirical work that has analyzed this question, and the overall conclusion is unequivocal: $\mathrm{AD}$ is to a great extent being used in a retaliatory fashion.

Prusa and Skeath (2001), for example, have undertaken an extensive empirical study in which they analyze the trends in worldwide AD filing during the past two decades. To do so, they use data on all AD cases filed or reported to the GATT/WTO between 1980 and 1998 to test for evidence of economic and strategic motives. In terms of the former, they look for evidence of AD cases being filed against large suppliers or suppliers who have large percentage surges in imports. In terms of strategic motives, they look for indications of "club" or retaliatory filings of AD cases. "Club" filings refer to the use of AD against countries that have previously used this instrument themselves, regardless of whom they have used it against. Retaliatory filings, on the other hand, are those carried out by a country against trading partners that have in turn used AD against it in the past.

Their results seem to provide strong support for the strategic view of antidumping. In particular, they find that one-half of all AD cases filed between 1980 and 1998 are consistent with retaliation incentives. These results, by which the observed use of AD seems to be consistent with strategic motives, are consistent with earlier studies and have been confirmed by later research. ${ }^{38}$ Feinberg and Reynolds (2006), for example, analyze WTO data on AD filings by country and industry categories and also conclude that a substantial proportion of them are in line with retaliatory motives. More interestingly, their results suggest that retaliation is determined at the country level rather than by the industries directly involved. ${ }^{39}$.

Hence, the evidence regarding the use of $\mathrm{AD}$ is in line with our theoretical findings. First of all, note that - if interpreted in an extreme way - the aforementioned evidence indicates that there

\footnotetext{
${ }^{37}$ The use of $\mathrm{AD}$ duties under such circumstances is allowed by the GATT/WTO code whenever the dumped imports are proven to have caused material injury to domestic firms.

${ }^{38}$ Finger (1993) has argued that countries that use AD tend to apply it against each other, and not against countries that do not use this instrument to begin with. To back this claim, he notes that during the 1980's approximately two thirds of AD cases were filed against countries who also used this type of duties. Along the same lines, Prusa (2001) has argued that many countries appear to file for $\mathrm{AD}$ duties against countries who have done the same to them in the past. Vandenbussche and Zanardi (2008) find that retaliation plays an important role in a country's decision to adopt antidumping laws.

${ }^{39}$ Blonigen and Bown (2003) also analyze filing decisions at the industry level for the United States. They find that the use of $\mathrm{AD}$ is affected by the threat of retaliation through the same channel. In particular, industries seem less likely to initiate petitions against firms from countries which have active AD provisions and are at the same time an important destination for their exports.
} 
is no such thing as antidumping measures, only premiums added to tariffs for strategic reasons. ${ }^{40}$ Moreover, the use of $\mathrm{AD}$ seems to be significantly influenced by political lobbying, at least in the United States. Hence, our model, in which countries adjust their tariffs in a discretionary manner according to political preferences seems appropriate to think about AD measures. ${ }^{41}$ In such a model, a theory of retaliatory AD is essentially a theory of retaliatory tariffs, and - as long as political preferences change over time and are not perfectly observed - retaliatory tariffs are useful to maximize the joint welfare of governments.

But what is it that makes the model of Section 5 more appealing as a model of AD than, say, as a model of safeguards? In the first place, and as we said earlier, the use of AD is highly discretional. Safeguards, on the other hand, are regulated in a way that discourages governments from using them arbitrarily. The Agreement on Safeguards and Article XIX of GATT 1994 provide that a WTO member may apply safeguard measures only if, following an investigation by competent authorities, it determines that imports have increased, that the increase was a result of unforeseen developments and that the increased imports have caused, or threatened to cause, its domestic industry to suffer serious injury. Thus, the standard for establishing injury is substantially stricter under a safeguard action than under AD regulations. ${ }^{42}$ There is an additional aspect of safeguards that make them very unappealing relative to $\mathrm{AD}$ for retaliatory purposes: whereas it is possible to target a specific country through the use of AD measures, safeguards must be applied in a nondiscriminatory manner. In our two-country model, of course, the ability to apply discriminatory tariffs to different trading partners is inconsequential. In a multi-country world, though, it is evident that this ability becomes crucial for the effective use of retaliation. Finally, a major guiding principle of the Agreement on Safeguards is that the country imposing them must pay compensation to the country whose trade is affected. In this sense, the use of safeguards is closer to our characterization of a reciprocal equilibrium than it is to retaliation. ${ }^{43}$

\footnotetext{
${ }^{40}$ Of course, some of the use of $\mathrm{AD}$ does in fact respond to the existence of dumped imports: in any case, the latter can be explained through the traditional economic reasoning, and our model deals only with the retaliatory use of this instrument.

${ }^{41}$ Our model incorporates one key ingredient that seems realistic while making retaliation necessary on equilibrium: private information. Indeed, if all parameters were publicly known in our world, governments could support full cooperation without resorting to retaliation. In this case, governments would simply set their tariffs at their politically optimal values given the realization of parameters, and any deviation would be punished through Nash reversion. It is the presence of private information, together with the need to provide proper incentives, that makes retaliation useful.

${ }^{42}$ Indeed, the criteria for applying safeguards are not straightforward to meet. Regarding the application of US safeguards on steel in 2002, for example, a WTO Panel found that the US had failed to provide an adequate explanation of their conclusion (1) that imports had increased; (2) that a causal link existed between the increased imports and serious injury to the domestic industry; and (3) that the increased imports had resulted from unforeseen developments.

${ }^{43}$ To be precise, the Agreement on Safeguards recently relaxed the need to accompany safeguard measures with appropriate compensation. Indeed, if the original safeguard measure is taken based on an absolute increase in imports and otherwise conforms to the provisions of the Agreement, it is now possible for the damaged country to have to
} 


\subsection{Evidence on $\mathrm{AD}$ and DSU}

Besides retaliating through the use of trade measures, governments could use the DSU. It could be, though, that challenging a trade measure in the DSU is costly and entails some uncertainty, so direct retaliation might be preferable whenever it is feasible. Do governments use the DSU? Bown (2005) provides evidence on this issue. In particular, he analyzes the determinants of WTO members' decisions of whether to use the DSU to challenge trade remedies imposed by the United States between 1992 and 2003. At first glance, the evidence suggests that countries challenge a low proportion of trade remedies in the DSU. During the aforementioned period, for example, the United States applied a total of 178 AD measures against other WTO members, of which only 29 were challenged. As for the factors that determine a country's decision to file a formal complaint in the DSU, Bown finds that standard economic determinants are important. More interesting in light of our results, he looks at the relationship between the foreign country's ability to retaliate through an AD measure on the U.S. industry's export and that country filing a complain at the WTO ${ }^{44}$ His finding, that such a relationship is statistically significant and negative, is "consistent with the theory that WTO complainants may be avoiding WTO litigation in favor of pursuing reciprocal antidumping and hence vigilante justice". ${ }^{45}$

\section{Concluding remarks}

We have developed a model showing that, in a world of restricted trade instruments, the use of retaliatory tariffs might play a useful role. We have then argued that retaliation is observed in the use of $\mathrm{AD}$ : as the tariffs in our model, $\mathrm{AD}$ measures can be applied in a fairly discretionary manner and they can be targeted against a specific country. On the contrary, safeguards do not share any of these properties and we observe that they remain relatively unused. Of course, countries could also use the DSU to file formal complaints against trade remedies imposed by their trading partners. The evidence, however, suggests that most trade measures are not formally challenged, and that they are less likely to be challenged if the affected country has the ability to retaliate directly.

Even though our model is admittedly stylized, we feel that it succeeds in illustrating a simple idea while being consistent with the evidence regarding the use of $\mathrm{AD}$. In a world of restricted instruments, the strategic or retaliatory use of the remaining ones may be the most efficient way to

wait for three years before it can retaliate. As was mentioned earlier, though, the provisions regarding the application of safeguards are quite strict, and the practical relevance of this modification is therefore not obvious. Bown (2002) notes that safeguards have remained unused relative to AD even after this modification.

${ }^{44}$ As a proxy for a foreign country's ability to retaliate directly, Bown (2005) uses the share of the protected U.S. industry's value of domestic production that is exported to that country.

${ }^{45}$ See Bown (2005). 
deal with hidden information. In Tinbergen's (1967) terms, it could be said that the instruments available to countries should be analyzed jointly and in relation to the objectives which are to be attained. We believe that this should be kept in mind when designing rules for international cooperation since, in restricting the use of some of the instruments usually available to governments, these rules might trigger the use of other instruments in new and unforeseen ways.

\section{Appendix}

\subsection{Repeated model with transfers and tariffs}

In the presence of transfers and tariffs, the interim welfare of Home is defined as

$$
W^{H}\left(\sigma^{H}, C, \zeta^{H}\right)=W_{x}^{H}\left(\tau_{x}^{H^{*}}\left(\hat{\zeta}^{H}\right), \zeta^{H}\right)+T^{H}\left(\hat{\zeta}^{H}\right)+\frac{1}{N} \sum_{\zeta^{F} \in \bar{\zeta}}\left[W_{y}^{H}\left(\tau_{y}^{F^{*}}\left(\zeta^{F}\right)\right)-T^{F}\left(\hat{\zeta}^{F}\right)\right]+v
$$

where we assume the use of an obedient tariff rule and $\tau_{x}^{H^{*}}\left(\hat{\zeta}^{H}\right)$ denotes the politically-optimal tariff, $T^{H}\left(\hat{\zeta}^{H}\right)$ denotes the transfer implied by the coordination scheme and $v$ represents the continuation payoff.

Local on-schedule incentive compatibility then requires that

$$
W_{x}^{H}\left(\tau_{x}^{H^{*}}\left(\zeta^{H}\right), \zeta^{H}\right)+T^{H}\left(\zeta^{H}\right) \geq W_{x}^{H}\left(\tau_{x}^{H^{*}}\left(\hat{\zeta}^{H}\right), \zeta^{H}\right)+T^{H}\left(\hat{\zeta}^{H}\right)
$$

for all $\zeta^{H}, \hat{\zeta}^{H} \in \bar{\zeta}$ and $\hat{\zeta}^{H}>\zeta^{H}$, or

$$
T^{H}\left(\zeta^{H}\right)-T^{H}\left(\hat{\zeta}^{H}\right) \geq W_{x}^{H}\left(\tau_{x}^{H^{*}}\left(\hat{\zeta}^{H}\right), \zeta^{H}\right)-W_{x}^{H}\left(\tau_{x}^{H^{*}}\left(\zeta^{H}\right), \zeta^{H}\right)
$$

Obviously, then, any instruction rule that calls for the use of politically-optimal tariffs and a transfer function satisfying,

$$
\begin{aligned}
T^{H}\left(\zeta_{1}\right) & =0 \\
T^{H}\left(\zeta_{i}\right)-T^{H}\left(\zeta_{i+1}\right) & =W_{x}^{H}\left(\tau_{x}^{H^{*}}\left(\zeta_{i+1}\right), \zeta_{i}\right)-W_{x}^{H}\left(\tau_{x}^{H^{*}}\left(\zeta_{i}\right), \zeta_{i}\right) \text { for } i=1,2, \ldots, N,
\end{aligned}
$$

will be enough to achieve efficiency while satisfying on-schedule incentive compatibility constraints. Let $\hat{T}^{j}\left(\zeta^{j}\right)$ denote a transfer function satisfying (26). In the first place, such an instruction rule will make it optimal for the government of the importing country to truthfully reveal its type, for the simple reason that the incentive to over-represent disappears through the transfer. ${ }^{46}$ Additionally,

\footnotetext{
${ }^{46}$ Global incentive compatibility is given by the fact that our model satisfies the single-crossing property, since the
} 
efficiency is guaranteed by the fact that the instruction rule entails the use of politically-optimal tariffs for all reports: since the latter will be truthful, import tariffs will consequently be set at their efficient levels.

The last issue we need to address is whether the off-schedule incentive compatibility constraints are satisfied. In other words, will both governments use efficient tariff rules? Since, as we said before, observable deviations trigger Nash reversion, this will be the case if governments are sufficiently patient. This proves our proposition.

\subsection{Repeated model with tariffs and subsidies}

The idea behind Equations (13) and (14) in the main body of the paper is as follows: suppose that governments agree ex-ante on some arbitrary values for world prices. Equation (14) basically says that world prices will always remain at those levels, since import tariffs and export subsidies will respond to announcements in such a way as to keep them invariant. Thus, tariffs and subsidies will always lie on the same iso-world price locus regardless of announcements. However, the exact point on the locus on which they lie will depend on announcements, since efficiency requires that Equations (13) be satisfied at all points in time. Therefore, Equations (13) and (14) jointly state that tariffs and subsidies in each market should be set at the intersection of some pre-specified iso-world price locus and the efficiency locus corresponding to the announcement.

If we denote tariffs and subsidies satisfying Equations (13) and (14) by $\hat{\tau}_{x}^{H}\left(\hat{\zeta}^{H}\right)$ and $\hat{\tau}_{x}^{F}\left(\hat{\zeta}^{H}\right)$, a rule instructing governments to set their tariffs and subsidies at such levels would satisfy both efficiency and incentive compatibility for the government of the importing country. ${ }^{47}$ These conditions are very intuitive: the desire to overclaim one's type arises from the potential benefit of favorably affecting the terms of trade. However, if the coordination scheme is such that the exporting country's subsidy decreases so as to eliminate the terms-of-trade effect associated to each report, there is no incentive to lie about one's type. This, in turn, can always be done in our setting since there is no private information regarding the export sector. Efficiency comes from the observation that, in the present model, all that matters for total welfare is the difference between import tariffs and export subsidies: as long as this difference is equal to the politically-optimal import tariff, total welfare is maximized. ${ }^{48}$

\footnotetext{
marginal welfare of an increase in the domestic price of the import good increases with the realization of the political economy parameter $\zeta$.

${ }^{47}$ Efficiency rests on the assumption of private information only in the import side of the market. Thus, tariffs and subsidies need only be adjusted in response to the importing country's announcement in order to achieve efficiency. Global incentive compatibility, on the other hand, stems once again from the fact that the marginal welfare of an increase in the domestic price of the import good is increasing in $\zeta$.

${ }^{48}$ This can be seen from the fact that, when we add governments' welfare in any one market, the joint welfare depends only on; a) the difference between the import tariff and the export subsidy, and b) local prices. The latter,
} 
Figure 1 illustrates the discussion. Suppose the world price is set at a pre-specified level which we denote $\bar{p}_{x}^{W}$ : the downward sloping iso-world price locus shows all the combinations of import tariffs and export subsidies that deliver this price in equilibrium. Given two values of the political economy parameter in Home, $\zeta_{1}^{H}$ and $\zeta_{2}^{H}$ where $\zeta_{2}^{H}>\zeta_{1}^{H}$, the upward sloping loci represent the efficiency frontiers, i.e., combinations of tariffs and subsidies that maximize joint welfare. ${ }^{49}$ All the mechanism does is to instruct, for each announcement made by the importing country, the tariffsubsidy pair that lies on the intersection of the iso-world price line and the corresponding efficiency locus: in this way, world prices are kept constant, eliminating the terms-of-trade externality while achieving efficiency.

[Insert Figure 1 here]

Finally, since such a mechanism maximizes joint expected welfare, world prices in both markets can always be chosen so as to avoid off-schedule deviations in the presence of Nash-reversion if governments are sufficiently patient. Proposition 2 summarizes the previous discussion.

\section{References}

[1] Athey, S., Bagwell, K., 2001. Optimal collusion with private information. Rand Journal of Economics 32.3, 428-465.

[2] Athey, S., Bagwell, K., Sanchirico, C., 2004. Collusion and price rigidity. Review of Economic Studies 71.2, 317-350.

[3] Bagwell, K., Staiger, R.W., 1990. A theory of managed trade. American Economic Review 80, 779-795.

[4] Bagwell, K., Staiger, R.W., 2001. Reciprocity, non-discrimination and preferential agreements in the multilateral trading system. European Journal of Political Economy 17, 281-325.

[5] Bagwell, K., Staiger, R.W., 2005. Enforcement, private political pressure and the GATT/WTO escape clause. The Journal of Legal Studies 34, 471-513.

[6] Baldwin, R., 1987. Politically realistic objective functions and trade policy, Economic Letters 24, 287-290.

[7] Barfield, C., 2004. High-tech protectionism: the irrationality of antidumping laws. Book Summary, American Enterprise Institute for Public Policy Research.

in turn, depend only on the former (see Section 2).

${ }^{49}$ Obviously, they yield the same joint welfare as the pair $\left(\tau_{x}^{H^{*}}\left(\zeta^{H}\right), 0\right)$. 
[8] Blonigen, B., Bown, C., 2003. Antidumping and retaliation threats. Journal of International Economics 60.2, 249-273.

[9] Bown, C., 2002. Why are safeguards under the WTO so unpopular? World Trade Review 1, 47-62.

[10] Bown, C., 2005. Trade remedies and World Trade Organization Dispute Settlement: why are so few challenged? Journal of Legal Studies 34.2, 515-555.

[11] Feenstra, R., Lewis, T,.1991. Negotiated trade restrictions with private political pressure. The Quarterly Journal of Economics 106.4, 1287-1307.

[12] Feinberg, R., Reynolds, K., 2006. The spread of antidumping regimes and the role of retaliation in filings. Southern Economic Journal 72.4, 877-890.

[13] Finger, J.M., (Ed.), 1993. Antidumping, Ann Arbor, MI, University of Michigan Press.

[14] Francois, J.F., Niels, G., 2004. Political influence in a new antidumping regime. Tinbergen Institute Discussion Paper TI 2004-011/2.

[15] Fudenberg, D., Levine, D., Maskin, E., 1994. The folk theorem with imperfect public information. Econometrica 62.5, 997-1039.

[16] Green, E., Porter R., 1984. Noncooperative collusion under imperfect price information. Econometrica 52.1, 87-100.

[17] Hansen, W., 1990. The International Trade Commission and the politics of protectionism. American Political Science Review 84, 21-46.

[18] Hansen, W., Prusa, T.J., 1997. The economics and politics of trade policy: an empirical analysis of ITC decision making. Review of International Economics 5, 230-245.

[19] Hungerford, T.L., 1991. GATT: A cooperative equilibrium in a noncooperative trading regime. Journal of International Economics 31, 357-369.

[20] Klitgaard T., Schiele, K., 1998. Free versus fair trade: the dumping issue. Current Issues in Economics and Finance, Federal Reserve Bank of New York 4.8.

[21] Moore, M.O., 1992. Rules or politics?: an empirical analysis of ITC antidumping decisions. Economic Inquiry 30, 449-466. 
[22] Park, J.-H., 2000. International trade agreements between countries of asymmetric size. Journal of International Economics, 50, 473-95.

[23] Prusa, T.J., 2001. On the spread and impact of antidumping. Canadian Journal of Economics $34,591-611$.

[24] Prusa, T.J., Skeath, S., 2002. The economic and strategic motives for antidumping filings. Weltwirtschaftliches Archiv 138.3, 389-413.

[25] Prusa, T.J., Skeath, S., 2004. Modern commercial policy: managed trade or retaliation?, in Choi, E.K., Hartigan, J.C. (Eds.), The Handbook of International Trade Vol II: Economic and Legal Analysis of Trade Policy and Institutions, Blackwell, London, 358-382.

[26] Riezman, R., 1991. Dynamic tariffs with asymmetric information. Journal of International Economics 30.3, 267-283.

[27] Tinbergen, J., 1967. Economic Policy: Principles and Design", Rand McNally.

[28] Vandenbussche, H., Zanardi, M., 2008. The proliferation of antidumping laws. Economic Policy 23(53), 93-138. 